\title{
Protocolo de avaliação morfossintática por amostra espontânea: construção e validação
}

\begin{abstract}
RESUMO
A utilização de instrumentos de avaliação clínica na área da Fonoaudiologia é muito comum, entretanto, no Brasil há escassez de instrumentos, em particular na área de avaliação morfossintática. O objetivo foi construir, validar e obter valores de referência preliminares para um protocolo de avaliação morfossintática (PAM) por meio da amostra de fala espontânea. O estudo foi dividido em três etapas: 1 - construção do protocolo, 2 validação de conteúdo e critério e 3 - obtenção de valores de referência. Para a construção do protocolo foi realizada revisão narrativa da literatura e elencadas categorias presentes nos modelos evolutivos de aquisição morfossintática para elaboração de uma versão inicial. Na validação de conteúdo o instrumento foi aplicado e analisado, por meio de um questionário, por três profissionais da área da linguagem. Foi usado o Índice de Fidedignidade entre os juízes para comparação dos resultados da aplicação do protocolo e os testes Alpha de Cronbach, Spearman e Brown e Índice de Validade de Conteúdo/IVC nas respostas do questionário. Para a validação de critério e obtenção dos valores de referência o protocolo foi aplicado em amostras de fala de 10 crianças com Transtorno no Desenvolvimento da Linguagem (TDL) e 25 crianças com Desenvolvimento Típico de Linguagem (DTL) entre 30 a 60 meses. Os dados gerados pela aplicação do PAM nos dois grupos foram submetidos à análise estatística descritiva e ao teste Mann-Whitney e os valores de referência foram calculados por meio do desvio padrão dos grupos para definição de parâmetros e delineamento do perfil sintático das faixas etárias. O resultado final da construção do protocolo gerou um instrumento com nove itens para avaliação morfossintática da linguagem. Os resultados dos testes estatísticos aplicados na validação de conteúdo legitimaram a fidedignidade do instrumento com índices considerados substanciais tanto para coeficiente alpha, maior que 0,80 , Spearman e o teste IVC teve conceito máximo de 1,0. Na validação de critério os resultados indicaram, por meio das médias, que as crianças com TDL possuem repertório deficitário de habilidades sintáticas comparadas ao grupo com DTL. Na obtenção dos valores de referência foi possível verificar a presença de critérios com variação em grau de significância, maior ou menor peso, no entanto, todos foram necessários para o cálculo geral e enquadramento da
\end{abstract}


criança na faixa de referência. Portanto, o protocolo foi construído com base na literatura e gramática da língua portuguesa. Em relação ao conteúdo do protocolo, houve conformidade e compatibilidade nas respostas dos especialistas o que revela confiabilidade. Os resultados dos testes estatísticos legitimam a fidedignidade com índices considerados substanciais tanto para coeficiente Alpha, como Spearman. A validade de critério foi atestada, já que o PAM distinguiu com significância crianças com DTL daquelas com TDL por meio da maioria dos itens de análise do protocolo. Desta forma, o PAM pode auxiliar na caracterização do perfil sintático de crianças com alterações no desenvolvimento de linguagem, mas é importante destacar que o processo de validação deve ser reafirmado por ter sido realizado na mesma amostra da construção e os valores de referência aferidos.

Palavras chaves: Aquisição de Linguagem Infantil; Transtorno no Desenvolvimento da Linguagem; Morfossintaxe. 